\title{
Editorial
}

\section{Recommendations on nutrition to improve cardiovascular health of population of Kyrgyzstan in light of AHA dietary guidance 2021}

Recently new AHA dietary guidance to improve cardiovascular (CV) health 2021 was released (1). The document is a very comprehensive guide on healthy nutrition to attain $\mathrm{CV}$ health and recommends:

- to adjust the energy intake according to expenditure;

- to eat plenty of fruits and vegetables;

-to choose food made of whole grains instead of refined grains;

-sources of protein are plant proteins; fish and seafood; low-fat or fat free dairy products; if meat, poultry then non-processed and of lean cuts;

-to use plant oil instead of subtropical oils and animal fat;

-to minimize beverages and drinks with sugar and cook meal without or little salt (1).

Some recommendations need to be adjusted to different populations with diverse nutrition and eating culture. The tables are on energy expenditure are good but complex for population so they might be used by healthcare professionals instead. In Kyrgyzstan, high altitude country, it might be challenging to control salt consumption in rural areas as national dishes are usually salty, so we should promote reduction of its use while cooking and removing from table in households. In addition, the potential challenge is the scarcity of vegetables and fruits in remote high-altitude areas especially during winter season.

We present here recommendations to our population for healthy nutrition in light of this guidance paper.

Energy intake and expenditure should be regulated to maintain a healthy body weight. Maintaining a healthy body weight throughout life is an important component in reducing the risk of $\mathrm{CV}$ diseases. In the last 10 years, sedentary lifestyle and increased energy intake have been noted, leading to a positive energy balance and accumulation of excess body weight (2). However, energy requirements are affected by age, gender, and level of physical activity $(3,4)$. Large portion size, even for healthy meals, can promote positive energy balance and weight gain (5). Therefore, there is a need to introduce rapid dietary assessment tools to reduce CV diseases throughout the lifespan and track diet in electronic medical records (6).

We recommend to use smaller portions for meals - f.e. $300 \mathrm{mg}$ for the first serving, $200 \mathrm{mg}$ for the second serving, $150 \mathrm{mg}$ for salad and $150 \mathrm{ml}$ for juice or water or tea. The old recommended large portions sizes were mostly driven by the fact of hard manual labor required large energy expenditure; however, in modern era of technical advancements, there is no need for large portions as they just enlarge stomach and reflectory increase appetite (7).

We recommend consuming whole fruits and vegetables, which are rich in dietary fiber that provides satiety, as opposed to consuming juices (8). All kinds of fruits and vegetables (fresh, frozen, canned and dried) can be included in the diet and are good for the heart. However, canned fruits and vegetables with added sugar and salt should be limited.

We recommend consuming whole grains, as well as those that contain intact starch, germ, endosperm and bran, they are rich in fiber. Whole grains reduce the risk of developing coronary artery disease (9) and reduce CV risk factors (10).

Eating plant-based proteins (legumes and nuts) that are a source of fiber may help reduce the risk of heart disease (11). Higher nut intake has been shown to be associated with a lower risk of death from CV diseases, coronary artery disease, and stroke (10-12). Consumption of plant-based meat substitutes requires some caution as they contain sugar, saturated fat, salt, stabilizers and additives $(13,14)$.

Regular consumption of fish and seafood is recommended, which is associated with a lower development of CV diseases. Eating 2-3 servings of fish per week has been reported in the literature to reduce mortality from CV disease, coronary artery disease, myocardial infarction, stroke, and heart failure, which is associated with omega-3 fatty acid content (15-17).

Address for Correspondence: Feruza Kochkorova, Department of Hygienic disciplines, Kyrgyz State Medical Academy, Bishkek, Kyrgyzstan Email:

Received: Accepted: Copyright @2022 Heart, Vessels and Transplantation 
If you choose poultry or meat, they should be lean without fat. Horse meat is in ration of people of Kyrgyzstan, it is lean and composed of unsaturated fat. However the smoked and salty horse meat products should not be used in large proportions, instead the fresh-cooked horse meat once a week may be advised (expert opinion). There are studies that horse meat consumption reduces total and low-density lipoprotein (LDL) cholesterol, and thus the risk of CV diseases (18, 19).Del Bo et al. demonstrated in their randomized controlled study that consumption of horse meat during 90 days in healthy males was associated with significant reduction of total and LDL cholesterol (by 6.2 and 9.1\%) and increase in polyunsaturated fatty acids by $8 \%(19)$.

Thus, including in the diet an increased amount of fruits, vegetables and fish, as well as a reduction in sugar and salt, the transition from fatty to lean meat, helps to reduce the development of coronary artery disease and mortality from CV diseases.

The main sources of polyunsaturated fatty acids vegetable oils: soybean, corn, safflower, sunflower, walnuts and flax seeds, reduce the concentration of cholesterol, LDL, and reduce the progression of atherosclerosis (20). Of note, chronic consumption of trans fatty acids adversely affects cardiometabolic risk factors for CV diseases (21).

A positive relationship has been noted in the literature between dietary cholesterol and LDL-cholesterol concentrations; however, the current cholesterol intake in the US is $300 \mathrm{mg} /$ day (22). Eat more unrefined foods $(13,23,24)$. Consumption of ultra-processed (refined) foods can lead to overweight, obesity, cardiometabolic disorders (type 2 diabetes, CV disease) (25-27).

In the prevention of cardiovascular diseases, it is recommended to consume Kyrgyz national drinks: airan, saamal, kymys, zharma, maksym, chalap.

We recommend products, and dishes with a small amount of salt and sugar. Literature evidence suggests a direct relationship between salt intake and high blood pressure (28).

Research in healthy eating should focus on accurate, actual nutrition to determine the impact on health, not just what is eaten, but why, when, and how one eats throughout life (29). Dietary studies should take into account individual differences in diet, eating behavior, microbiome, genetic background, and socioeconomic and physical environments that influence the incidence of CV disease (29-31). In the future, these factors will help to reduce socioeconomic, racial, and ethical disparities in diet and cardiovascular disease outcomes
(31, 32), which should be taken into account when designing diets and preventing CV disease.

Marina K. Esenamanova, Feruza A. Kochkorova, Tatiana A. Tsvinskaya Department of Hygienic disciplines, IK Akhunbaev Kyrgyz State Medical Academy, Bishkek, Kyrgyzstan

Peer-review: Internal Conflict of interest: None to declare Authorship: M.K.E., F.A.K., T.A.T. equally contribute to preparation of manuscript Acknowledgement and funding: None to declare

\section{References}

1.Lichtenstein AH, Appel $L$, Vadiveloo M, Hu FB, KrisEtherton PM, Rebholz PM, et al. 2021 dietary guidance to improve cardiovascular health: A scientific statement from the American Heart Association. Corculation 2021; 2. US Department of Agriculture and US Department of Health and Human Services. Dietary Guidelines for Americans 2020-5. 9th ed. December 2020.

3.Van Horn L. Calories count: but can consumers count on them? JAMA 2011; 306: 315-6.

4. Van Horn L, Carson JA, Appel LJ, Burke LE, Economos C, Karmally W, et al; on behalf of the American Heart Association Nutrition Committee of the Council on Lifestyle and Cardiometabolic Health; Council on Cardiovascular Disease in the Young; Council on Cardiovascular and Stroke Nursing; Council on Clinical Cardiology; and Stroke Council. Recommended dietary pattern to achieve adherence to the American Heart Association/American College of Cardiology (AHA/ACC) Guidelines: a scientific statement from the American Heart Association. Circulation 2016; 134: e505-e529.

5. Vadiveloo M, Lichtenstein AH, Anderson C, Aspry K, Foraker R, Griggs $\mathrm{S}$, et al; on behalf of the American Heart Association Council on Lifestyle and Cardiometabolic Health; Council on Arteriosclerosis, Thrombosis and Vascular Biology; Council on Cardiovascular and Stroke Nursing; Council on Clinical Cardiology; and Stroke Council. Rapid diet assessment screening tools for cardiovascular disease risk reduction across healthcare settings: a scientific statement from the American Heart Association. Circ Cardiovasc Qual Outcomes 2020; 13: e000094.

6.Livingstone LBE, Pourshahidi LK. Portion size and obesity. Adv Nutr 2014; 5: 829-34.

7. Minich DM. A review of the science of colorful, plantbased food and practical strategies for "eating the rainbow." J Nutr Metab 2019; 2019: 2125070. 
8. Li Y, Hruby A, Bernstein AM, Ley SH, Wang DD, Chiuve $\mathrm{SE}$, et al. Saturated fats compared with unsaturated fats and sources of carbohydrates in relation to risk of coronary heart disease: a prospective cohort study. J Am Coll Cardiol 2015;66:1538-48.

9. Reynolds A, Mann J, Cummings J, Winter N, Mete E, Te Morenga L. Carbohydrate quality and human health: a series of systematic reviews and meta-analyses. Lancet 2019; 393: 434-45.

10. Viguiliouk E, Glenn AJ, Nishi SK, Chiavaroli L, Seider $\mathrm{M}$, Khan $\mathrm{T}$, et al. Associations between dietary pulses alone or with other legumes and cardiometabolic disease outcomes: an umbrella review and updated systematic review and meta-analysis of prospective cohort studies. Adv Nutr 2019; 10): S308-S319.

11. Kim Y, Keogh JB, Clifton PM. Does nut consumption reduce mortality and/or risk of cardiometabolic disease? An updated review based on meta-analyses. Int J Environ Res Public Health 2019;16: 4957.

12. Becerra-Tomás N, Paz-Graniel I, Kendall CWC, Kahleova H, Rahelić D, Sievenpiper JL, et al. Nut consumption and incidence of cardiovascular diseases and cardiovascular disease mortality: a meta-analysis of prospective cohort studies. Nutr Rev 2019; 77: 691709.

13. Monteiro CA, Cannon G, Levy RB, Moubarac J-C, Jaime $P$, Martins AP, Canella D, Louzada M, Parra D. NOVA. The star shines bright. Food classification. Public health. World Nutr 2016;7.

14. Gehring J, Touvier M, Baudry J, Julia C, Buscail C, Srour B,et al. . Consumption of ultra-processed foods by pesco-vegetarians, vegetarians, and vegans: associations with duration and age at diet initiation. J Nutr 2021; 151: 120-31.

15. Jayedi A, Shab-Bidar S. Fish consumption and the risk of chronic disease:

an umbrella review of meta-analyses of prospective cohort studies. Adv Nutr 2020; 11: 1123-33.

16. Krittanawong $C$, Isath A, Hahn J, Wang Z, Narasimhan B, Kaplin SL, et al. Fish consumption and cardiovascular health: a systematic review. Am J Med 2021; 134: 713-20.

17. Rimm EB, Appel L, Chiuve SE, Djoussé L, Engler MB, Kris-Etherton PM, Mozaffarian D, Siscovick DS, Lichtenstein AH; American Heart Association Nutrition Committee of the Council on Lifestyle and
Cardiometabolic Health; Council on Epidemiology and Prevention; Council on Cardiovascular Disease in the Young; Council on Cardiovascular and Stroke Nursing; and Council on Clinical Cardiology. Seafood long-chain n-3 polyunsaturated fatty acids and cardiovascular disease: a science advisory from the American Heart Association. Circulation 2018; 138: e35-e47.

18. Shakieva RA. Dissertation candidate medical science 1983. Bishkek. Kyrgyzstan.

19. Del Bo C, Simonetti P, Gardana C, Riso P, Luccini G, Ciapellano S. Horse meat consumption affects iron status, lipid profile and fatty acid compositionof red blood cells in healthy volunteers. Int J Food Sci Nutr 2013; 64: 147-54.

20. Hsu HY, Lin CJ, Lee YS, Wu TH, Chien KL. Efficacy of more intensive lipid-lowering therapy on cardiovascular diseases: a systematic review and meta-analysis. BMC Cardiovasc Disord 2020; 20: 334.

21. Wang DD, Hu FB. Dietary fat and risk of cardiovascular disease: recent controversies and advances. Annu Rev Nutr 2017; 37: 423-46.

22. Carson JAS, Lichtenstein AH, Anderson CAM, Appel $\mathrm{L}$, Kris-Etherton PM, Meyer KA, et al; American Heart Association Nutrition Committee of the Council on Lifestyle and Cardiometabolic Health; Council on Arteriosclerosis, Thrombosis and Vascular Biology; Council on Cardiovascular and Stroke Nursing; Council on Clinical Cardiology; Council on Peripheral Vascular Disease; and Stroke Council. Dietary cholesterol and cardiovascular risk: a science advisory from the American Heart Association. Circulation. 2020; 141: e39-e53.

23. Monteiro CA, Cannon G, Moubarac JC, Levy RB, Louzada MLC, Jaime PC. The UN Decade of Nutrition, the NOVA food classification and the trouble with ultraprocessing. Public Health Nutr. 2018;21:5-17.

24. Juul F, Vaidean G, Parekh N. Ultra-processed foods and cardiovascular diseases: potential mechanisms of action. Adv Nutr. Published online May 3, 2021.

25. Costa de Miranda R, Rauber F, Levy RB. Impact of ultra-processed food consumption on metabolic health. Curr Opin Lipidol 2021; 32: 24-37.

26. Zhang Z, Jackson SL, Martinez E, Gillespie C, Yang Q. Association between ultraprocessed food intake and cardiovascular health in US adults: a cross-sectional analysis of the NHANES 2011-2016. Am J Clin Nutr 2021;113: 428-36. 
27. Elizabeth L, Machado $P$, Zinöcker $M$, Baker $P$, Lawrence $M$. Ultra-processed foods and health outcomes: a narrative review. Nutrients 2020; 12: 1955. 28. Appel L, Brands MW, Daniels SR, Karanja N, Elmer PJ, Sacks FM; American Heart Association. Dietary approaches to prevent and treat hypertension: a scientific statement from the American Heart Association. Hypertension 2006; 47: 296-308.

29. Rodgers GP, Collins FS. Precision nutrition - the answer to "what to eat to stay healthy." JAMA 2020; 324: 735-6.
30. de Roos B, Brennan L. Personalised interventions-a precision approach for the next generation of dietary intervention studies. Nutrients 2017; 9: 847.

31. Ordovas JM, Ferguson LR, Tai ES, Mathers JC. Personalised nutrition and health. BMJ. 2018;361:bmj.k2173.

32. Hughes RL, Kable ME, Marco M, Keim NL. The role of the gut microbiome in predicting response to diet and the development of precision nutrition models. Part II: results. Adv Nutr 2019; 10: 979-98.

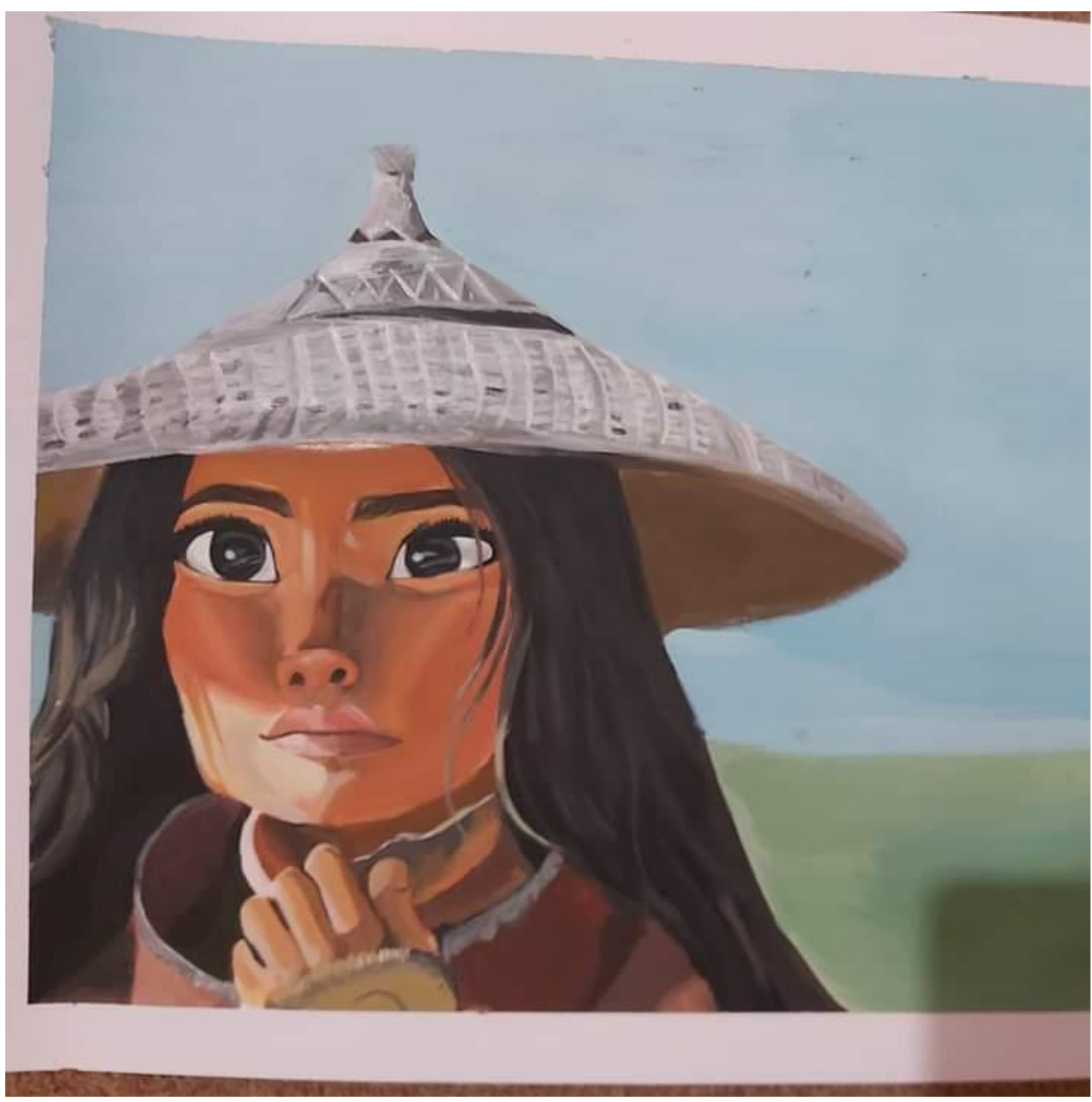

Oriental girl, city London. Art by Rihanna Rock (14 years old), London, United Kingdom. (published with permission of author and parent) 